\title{
The Operation for and the Importance of a Permanent Closeable Pancreatic Fistula.:
}

\author{
$\mathrm{By}$ \\ W. N. Boldyreff and W. F. Martin. \\ (From the Pavlov Physiological Institute of the Battle Creek \\ Sanitarium, Battle (reek, Michigan, U.S.A.)
}

Pancreatic juice is the most important of the digestive juices in the process of digestion and physiologists have long been trying to obtain it in its natural state (Regner de Graaf, 1664). For this purpose Cl. Bernard, C. Ludwig and others used a temporary fistula made by tying a glass cannula into the main pancreatic duct.

When such a fistula has been established the next day after the operation the juice begins to flow out through the cannula in abundant quantities. However, in about three to seven days the cannula falls out and the fistula heals up. This method is so simple and dependable that in Boldyreff's Laboratory Dr. V. N. Vorobievv (now Professor of Pediatrics in Kransnodar, Russia) having made thirty such fistulae did not lose a single dog. They all yielded pure zymogen juice in sufficient quantities. Besides the fact that such juice stops flowing soon (on the average not later than a week after the operation), it has another serious defect: it is much thinner that the juice obtained through vivisection and hence it was concluded that it is a product of abnormal irritation of the pancreas, and was therefore considered pathological.

R. Heidenhain and I. P. Pavlov, at about the same time, devised new methods for permanent pancreatic fiistula, which were rather similar and are well known. Both fistulae give active pancrea-

\footnotetext{
* Preliminary communication by Boldyreff, W. N., Byland, N. O., and Marti $n, W$. F., was published in an abstract in the American Physiological Journal, from Proceedings of the American Physiological Society, for the Annual Meeting, March, 1936.

A short description of this operation appeared in the Pavlov' 85th Jubilee Volume (1).
} 
tic juice. As a result physiologists celebrated a victory : an old dream had been realized at last, the fistula was not closed for months after the operation and at any time one could obtain through it normal pancreatic juice; which made it possible to study laws of secretion of pancreatic juice and its properties and effect upon food (I. P. Pavlov and his school). However, it soon became apparent that this victory was far from complete. Animals with other kinds of fistulae (salivary, gastric, intestinal, etc.) live for many years after the operation, yielding their respective juices, at the same time enjoying excellent health. Animals with pancreatic fistula (also fistula in ductus choledochus) as a rule die in a year's time, and sometimes within a few weeks after the operation, due to the loss of the pancreatic juice or bile.

The permanent loss of pancreatic juice (and bile) is always fatal and in both those cases which survive for a few months, definite pathological changes occur. These changes are apparent even in the first few days after the operation.*) I. P. Pavlov made a careful study of these and found that osteomalacia always developed. For that reason, after Heidenhain-Pavlov fistula has been devised attempts continued to be made for finding a better method.

About forty years ago Dr. Fodera ${ }^{3)}$ developed an operation for closeable pancreatic fistula which allowed only a portion of the juice to escape through the fistular opening. He introduced a T-shaped wire cannula into the pancreatic duct, which allowed only a portion of the juice to escape and therefore did not exhaust the animal. His idea was correct, but his method failed, because the cannula kept falling: out and the fistula healed as it does in Cl. Bernard's fistula.

There have been interesting cases when dogs operated after Pavlov's method for a pancreatic fistula, would live years in perfect health. I knew of two such animals which lived for more than three years, and in both the pancreatic fistula closed spontaneously so that in order to obtain some juice it was necessary each time to insert a temporary cannula into the opening of the duct on the skin. There is a sphincter around the opening of the pancreatic duct similar to that in ductus choledochus. It seems that sometimes during the operation for the pancreatic fistula there is some damage done to this sphincter and it can no longer open by itself and let the juice out. In order to obtain juice in such dogs it is necessary to insert a cannula (a tube) into the opening of the duct. This unintentional and advantageous injury to the sphincter happens very rarely. The fact that these dogs

*) See my article "The Pancreatic Triad." 2) 
as a rule did not lose a drop of their pancreatic juice outside, between experiments, was the reason for their excellent state of health and long life. The last third case of this sort was in my laboratory (at the Battle Creek Sanitarium). The dog was operated upon by my son Ephraim in I. P. Pavlov's method. The dog lived 6 years after the operation. Gradually he developed typical sugar diabetes in a severe form. Towards the end of his life blood sugar was over $0.5 \%$. There was glycosuria and other symptoms of diabetes (E. Bold y reff's data). We hardly used this dog for experiments and the disease has developed of its own accord.

There are other methods of operation for securing permanent pancreatic fistula for the purpose of obtaining zymogen pancreatic juice. They are similar in their principal points and differ only in technical details. These methods were offered by A. Frouin (1913), W. de P. Inlow (1921) ${ }^{5)}$ and W. N. Bold y reff $(1925),{ }^{6)}$ independently of each other (see ref. (4)). They are described in my article "Surgical Method".6) There is another fine operation by Ivy for the pancreatic fistula.

A. Ivy's ${ }^{7)}$ original method is interesting; it makes it possible to obtain juice from a portion of the gland (tail of pancreas in the dog). A similar operation has been more than once performed before Ivy (Minkowski, ${ }^{8)}$ Hedon, ${ }^{9)}$ Tiroloix ${ }^{10)}$ and others). But all former authors transplanted the tail of the pancreas for "internal "secretion and were not concerned about the external. Sometimes they even tied the duct during this operation. Ivy was the first one who used isolation of the tail of the pancreas for the purposes of studying the external secretion; his experiments were fully successful, and he also has carefully elaborated and described the technique of this operation. In 1928 he was kind enough to demonstrate to one of us (W. N. Bold yreff) an experiment on this operated dog in his Laboratory. Ivy's method if preferable because his dogs lose very little juice, outside of experiment, and therefore remain in good health a long time; the weak point of the method is the small amount of juice obtainable during experiments. But none of these methods is entirely satisfactory and as a result other methods have been attempted. And then W. N. Boldyreff found a new way to secure a closing pancreatic fistula, described below. Boldyreff's first operation was in 1934 and following this he was frequently assisted by Dr. N. O. Byl and, Dr. W. F. Martin, Dr. A. R. Dickson, Dr. H. Pudleiner, and Ephraim Boldyreff. In all we operated upon twelve dogs. All survived the operation ex- 
cept one which died from the surgical shock twelve hours after the operation.

A dog with such fistula was given a sufficient quantity*) of pure zymogen juice when necessary; all the other time the fistula is closed as easily and as safely as a corked bottle (see below).

This is the reason why such dogs remained in perfect health a long time in spite of the fistula.

\section{Description of the Operation.}

The new operation is an elaboration of the old Cl. Bernard method. The following description will enable the novices to follow it without consulting other literature.

A medium size dog, a female preferably, the last food taken two to three hours previous to operation. Make an incision of the abdominal wall along the median line about twelve centimeters long, starting at the ensiform cartilage. The stomach is grasped between two fingers, and then the fingers are moved in the direction of the duodenum, passing along the intestine about 15 centimeters, and drawing it outside, which bring the pancreas into view. Between the pancreas and the front wall of the duodenum we find the large pancreatic duct which is located about one inch (two centimeters) from the angle formed by the body and the tail of the pancreas, toward the stomach. The duct is recognized by its position, which is perpendicular to the intestine and by its whitish color and its size being about one centimeter long and one and one-half millimeters in thickness. Sometimes it is found free and open; but more commonly covered with connective tissue with small blood vessels in it. These must be carefully separated and dissected between two ligatures.

At the entrance of the duct into the intestine, with the aid of an intestinal needle, a ligature is inserted beneath it close to the intestinal wall. After this the duct soon fills with the juice and slightly dilates. For a distance of one-half centimeter or more the duct is then separated from the tissues in the direction of the pancreas and freed from connecting tissues, then inserted under it a thick strong ligature (either silk or ordinary thread), later to be tied on the neck of the cannula which is to be introduced into the duct.

With small, strong, sharp-pointed scissors we dissect the wall of the duct on a diagonal (not more than one-third or one-half of it) and

*) All the juice secreted by the gland. 
with the aid of a special guide introduce the cannula in the opening made for it. This opening is made about $\frac{1}{2} \mathrm{c}$. to the first ligature. ${ }^{*}$ As soon as a drop of water-transparent juice enters the cannula, the second ligature is securely fastened on the neck of the cannula. Its free end has, attached to it, a soft fine rubber tube about six to nine inches long. The other end of the rubber tube is placed over a glass tube bent at right angle (it is only one inch long). On the free distal end of this glass tube is fastened a hard rubber tube about nine inches long. It is essential that both soft and hard tubes be used. (Rous and McMaster ${ }^{11)}$ ). The first one (soft) is placed within the abdominal cavity, and the second (hard) under the skin (see Fig. 1). Care must be taken to avoid kinks in the tube. At first we used only the hard tube, placing one-half of it in the abdomen, but with not very good success as of two or three dogs treated in this manner one died from the surgical shock twelve hours after the operation, But when we used a soft tube all dogs survived. Next to the pancreatic duct, above and below, thick strong temporary ligatures are used under the

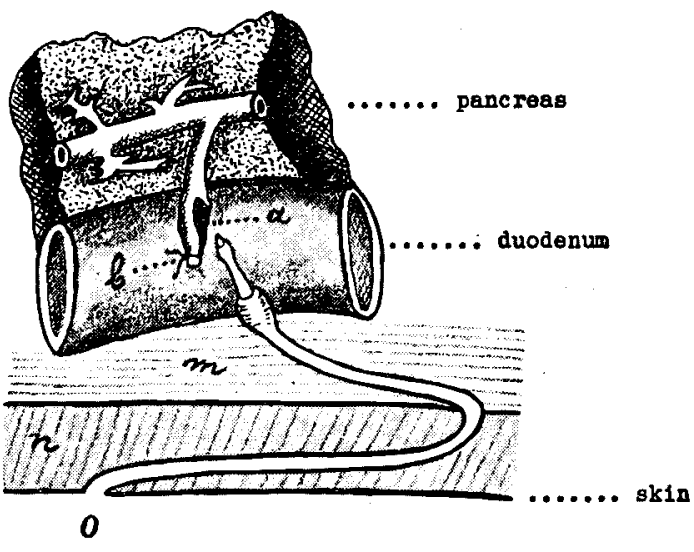

Fig. 1. Diagram

Position of the rubber tube in the abdomen and in the abdominal wall

Vertical section. The dog is standing. O-end of the hard rubber tube outside of the skin; $a$-the pancreatic duct, cut on a slant in order to insert the cannula; the duct is tied. $m$-the greater omentum; n-the abdominal wall.

*) In the Cl. Bernard method the cannula is inserted into the pancreatic duct but it always falls out in five or seven days. But in the method herein deseribed (see below) the cannula is attached in the same way, however it does not fall out but remains fastened to the duct for good, i.e. until the animal dies. What makes such a difference? In the first instance infection occurs because the cannula and the ligature go outside and as a result microbes digest the wall of the duct, the ligature does not hold and the cannula drops out. In the second instance infection does not occur because the cannula and the ligature are inside the abdomen and they are aseptic and the cannula remains in place. 
duodenum; each one goes through the abdominal wall and the skin and is tied after the operation in order to support the intestine in a secure contact with the abdominal wall until dependable adhesions are formed. We leave long ends on these ligatures, on the outside, over the skin, which makes it easier to find them later. They are removed twenty-four or thirty-six hours after the operation.

During the operation the delicate pancreas is handled with great care. The duodenum is placed deep in the wound directly under the opening in the abdominal wall and along the side of the incision. The cannula lies perpendicular to the line of the incision; the soft rubber tube attached to it is previously surrounded by omentum. The bent glass tube pierces only the muscles of the abdominal wall but not the skin in a way that enables the hard rubber tube on the other end of it to enter under the skin. We arrange this tube with the aid of a special instrument (see Fig. 2) under the skin around the abdominal incision

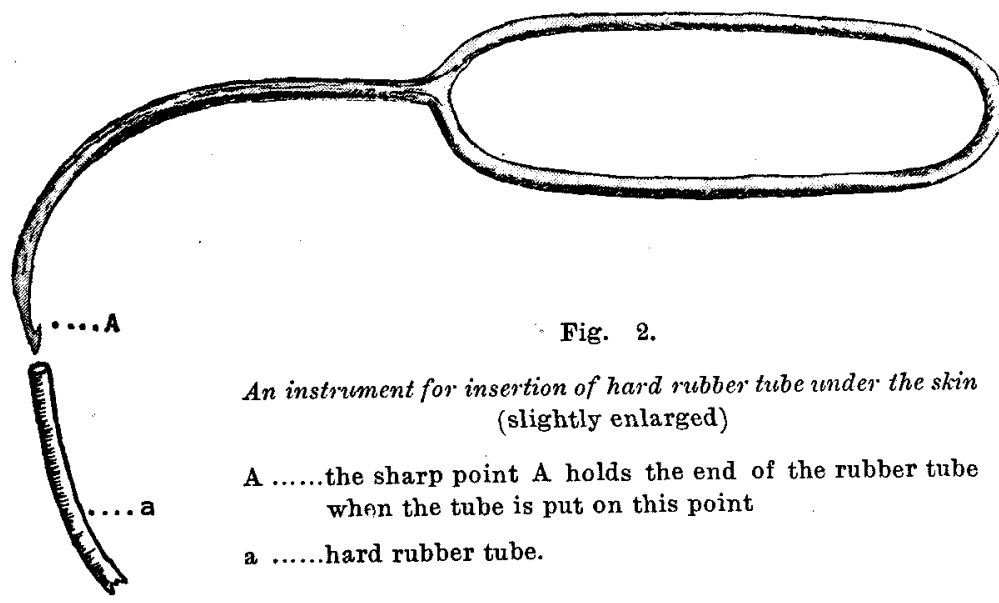

(see Fig. 3). It protrudes outside, not more than two or three imillimeters, thus preventing the dog from pulling it out with his teeth. We then suture the wound and tie the temporary supporting sutures. The wound is covered with some collodion.*)

*) The rubber tube attached to the cannula (soft in the abdomen and hard under the skin) is no innovation. In the old method of operation for the gastric fistula a thick rubber tube (the size of a little finger) used to be inserted into the stomach; it was laid along the outside wall of the stomach, covered in its folds and its distal end was fastened under the skin, just as in our new operation. One of us (W. N. Boldy$r e f f$ ) saw an operation of that kind performed on a human patient in this country, and previous to that he met a man who carried such a tube for several year, in Japan. 
The rubber tube should be inserted under the skin with the aid of a sharp thin sound (see Fig. 3 ); it is arranged around the wound in a specially constructed canal which should be as narrow as possible in order to avoid "pockets" which invite infection. This canal should have no outside openings in the skin and only the end "of the hard rubber tube comes through to the outside.*) It is advisable to cover such openings, and generally speaking skin wounds, with adhesive plaster which has been beforehand soaked in tincture of iodine and then dried.

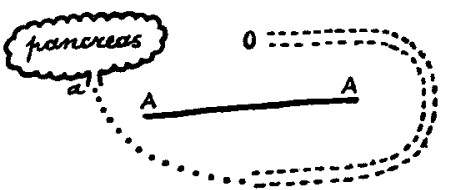

Fig. 3.

Position of the fistular rubber tube

View from above. The dog is lying on his back. Single dotted line indicates the position of the soft rubber tube coming from the pancreatic duct $a$ inside the abdomen, and the double broken lines indicate the position of the hard rubber tube under the skin.

$O$ - the end of the rubber tube outside the skin. $A-A$ - the incision in the abdominal wall for the operation.

In our first operations we did not observe these rules and therefore often had a lengthy and deep suppuration along the entire length of the tube, placed under the skin. We did not lose a single dog with this method, and constantly washing the wounds with quantities of iodine, we usually succeeded in checking the suppuration and the wounds would completely heal. But often during this long and obstinate struggle the dog would bite off all the hard rubber tube or even pull it out completely together with its soft portion and the cannula. The tighter the tube is fixed under the skin, the better it is protected against such interference by the dog. All these complications are avoided when there are no openings in the skin as described above.

It is likewise advisable to suture a bent glass tube, connecting the soft and the hard rubber tubes, to the subcutaneous connective tissue.

\section{Post-operative Treatment.}

The next important problem is how to protect the tube if its end is outside (and the wound) from being licked or pulled out by the dog's teeth.

*) A good way is not to let the end of the hard rubber tube outside at all, but to stop it with a glass or wooden stopper. When the dog recovers ( 1 or 2 weeks after the operations), one may use one of the following two ways of collecting juice: 1 . leading the end of the rubber tube ontside through a very small ineision in the skin; and 2. by inserting a syringe needle through the skin so that the pancreatic juice may flow through in outside. 
Some use a muzzle to avoid this. However, ordinary muzzles do not sufficiently protect the wound and the tube. One can use the special, long muzzle, like a cylinder surrounding the dog's mouth at a distance of one inch from the tip of the nose. (See Fig. 4.)

One can use a leather strap placed tightly around the dog's mouth as far as the eyes and fastened in some way. We succeeded in doing these with the aid of metal rings put through the cheek (in the same manner as earrings or rings in the lips of bulls in some countries, and rings in the lips of bears, in Russia and Europe). These rings

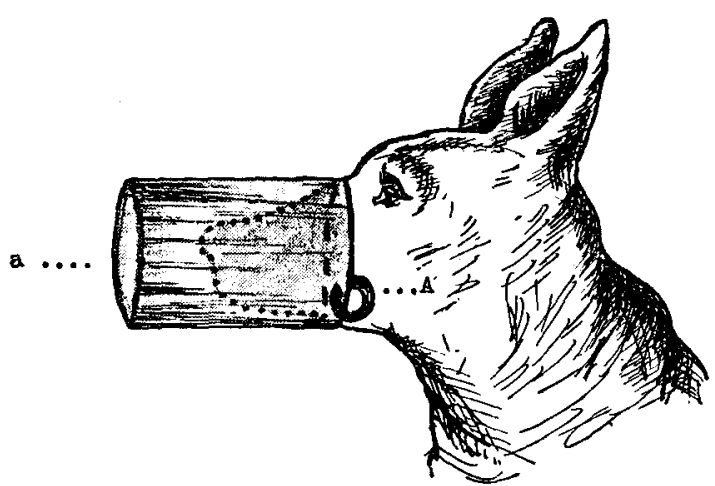

Fig. 4. Dog with a special muzzle a ......open end of the muzzle

A......ring in the skin holding the muzzle are easily inserted into the dog's cheek and the dogs stand them well, while muzzles usually irritate them.

We also tried covering the dog's abdomen and the fistular opening with a specially designed jacket or girdle. We attempted to protect the end of the fistular tube with special devices which were fastened to the skin in some way. But this problem is not completely solved.

The fistula may be closed to prevent the pancreatic juice flowing. outside; this is done by insertion of a glass, wooden or metal stopper, about one-half inch long, into the outside opening in the rubber fistular tube. If necessary it can be tightly tied on the outside over the rubber. tube. Several times we observed on our dogs that a closed tube would be pulled inside and the skin opening would soon heal up. Then we were forced to make a small skin incision under local anesthesia and pull out the end of the rubber tube or use a syringe needle.

\section{A Modified Method.}

There is another solution for this surgical problem (offered by W. $\mathrm{N}$. Boldyreff); one cannula is inserted into the main pancreatic duct, 
in the usual manner, and another cannula is introduced into one of the biliary ducts in direction toward the duodenum. The free ends of both cannulae are joined with a T-shaped glass tube, the vertical part of which is connected with a soft rubber tube further changing into a hard rubber tube. All this, except the hard rubber tube, is placed inside of the abdomen and wrapped by the greater omentum, and the hard rubber tube is led under the skin, as described above. We are planning to perform this modified method at the earliest opportunity.

This method is more complicated than the one we have tried out, but it is better in the sense that in this case pancreatic juice is not locked in the main duct and always has a free flow into the duodenum. Therefore there is no danger of degeneration of the pancreas. The end of the hard rubber tube going under the skin can be corked and opened again for the experiment when necessary (See Fig. 5).

Thus we can consider as solved the problem of the technique of the operation for a pancreatic fistula which may be temporarily closed, and when necessary opened again.

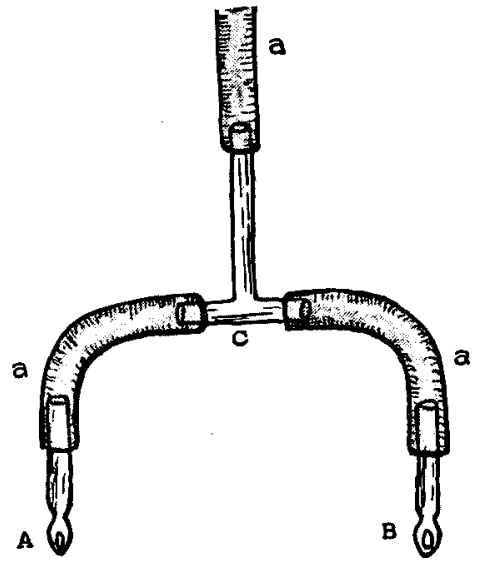

Fig. 5. Slightly enlarged Devise for the modifed operation for the closeable pancreatic fistula a-rubber tubes. $\quad \mathrm{C}-\mathrm{T}$-shaped glass tube. A-cannula inserted in the main pancreatic duct (in direction to outside). $B$-cannula inserted in one of the biliary ducts (in direction to the intestine).

\section{Discussion.}

Yet the problem of making a permanent pancreatic fistula using the whole gland is not solved, for the following reasons :

The pancreatic juice occupies a place by itself among other digestive juices, as we have found in our old and recent investigations. Loss of it outside is most harmful to the animal. It is probable that feeding pancreas or its preparations to the dog with a pancreatic fistula would improve the general condition of the fistular animal and the secretion of the pancreatic juice. Perhaps artificial introduction of natural pancreatic juice or ferments (Parke, Davis \& Co. and others 
or better dry pancreatic juice after Boldyreff ${ }^{12}$ ) into the organism of such dogs would be as beneficial for the animals as the administration of thyroid preparations is for people suffering from goiter. Once can draw gastric juice or saliva from animals every day in large quantities without harming them in the least. I. P. Pavlov had dogs who lived over ten years, while every other day he would obtain as much as a liter of gastric juice from each of them. These dogs were quite similar to milking cows and were in perfect health all the time.

The matter is different with the pancreatic juice. Loss of pancreatic juice causes illness of the dog, and stoppage of the duct often causes degeneration of the pancreas. One must dog these two dangers. Besides, it is further complicated by the fact that the pancreas is a very delicate organ.

Yet we had dogs with pancreatic fistulae who lived three years and more, and this gives us hope for the successful solution of the problem. It is probable that sometimes the main pancreatic duct is connected with the lesser pancreatic duct and then if the first one is closed, the juice flows freely into the intestine through the second duct. It is possible that in this case no degeneration of the pancreas follows.

Time will allow us opportunity to solve this question. But this may require long years. And now it is only two years since the first operation described in this paper for the pancreatic fistula. This dog died a few days ago from an accidental cause (another fistula) and now we must gather data on newly operated animals.

\section{REFERENCES.}

(1) Boldyreff, W. N.: The dry digestive juices in their "vital" state, their nature, means of their production and preservation. Pavlo v's Jubilee Volume, USSR Journal of Physiology, 1935, 17, 1292.

(2) Boldyreff, W. N.: The pancreatic triad. Amer. Journ. Med. Sc., 177, 778; Bull. of B.C. San. \& Hosp. Clinic, 1931, 26, 77.

(3) Fodera, Ph. A.: Permanente Pankreasfistel. Moleschott's Untersuchungen zur Naturlehre der Menschen und der Tiere, 1896, 16, 79.

(4) Frouin, A.: Nonvelle technique de la fistule pancreatique permanente. Compt. Rend. Soc. de Biol., 1913, 74, 1283.

(5) Inlow, W. de P.: A technic for the establishment of a permanent pancreatic fistula with the secretion of inactive proteolytic ferment. J. Lab. \& Clin. Med., 1921, 7, 86.

(6) Boldyreff, W. N.: Surgical method in the physiology of digestion. Description of the most important operations on the digestive system. Ergebnissed. Physiologie, 1925, T. 24, and Bull. Battle Creek Sanitarium \& Hospital Clinic, 1925, 20, 206.

(7) Ivy, A. C.: Contributions to the physiology of the pancreas. I. A method 
for the subcutaneous auto transplantation of the tail of the pancreas. Amer. Journ. Physiol., 1926, 77, 474.

(8) Minkowski, 1892. Berl. Klin. Wchnschr., 29, 90. 1893. Arch. f. expér. Path. u. Pharm., 31, 118. Cited by Ivy and Farrell (See reference 5).

(9) Hed on, 1892. Compt. Rend. Soc. de Biol., 44, 307, 687, 763. 1898. Travaux de physiologie, Paris, cited by He d on in Rev. de Med., 1919, 30, 622.

(10) Tiroloix, 1892. Arch. de Physiol., 24, series 5, IV, 617. 1892 a. Compt. Rend. Soc. de Biol., 44, 966. 1895. Compt. Rend. Soc. de Biol., 47, 256. Quoted by Ivy and Farrell (See reference 5).

(11) Rous, Peyton and McMaster, Philip D.: A Method for the Permanent sterile drainage of intraabdominal ducts, as applied to the common duct. Journ. of Exper. Med., 1923, 37, 11.

(12) Boldyreff, W. N.: Dry natural digestive juices: Their properties and laboratory and elinical use. Amer. Journ. Digest. Diseases and Nutrition, 1925, 2, No. 1. 